\title{
Mixture of biomass to energy reuse
}

\author{
W. C. Nozela ${ }^{1}$ C. E. M. Braz ${ }^{2}$ S. Almeida ${ }^{1}$ C. A. Ribeiro ${ }^{1}$ M. S. Crespi ${ }^{1}$
}

Received: 21 June 2016/ Accepted: 30 March 2017/Published online: 8 April 2017

(C) Akadémiai Kiadó, Budapest, Hungary 2017

\begin{abstract}
Focusing on the reuse of the energy and aiming at the thermal and kinetic characterization of sewage sludge and its mixture, with pruning residues (50 mass\%), the thermogravimetry was used. The kinetic study was elaborated from the local isoconversional integral method in heating rates $10.0,20.0$ and $30.0{ }^{\circ} \mathrm{C} \mathrm{min}{ }^{-1}$ at a temperature ranging from 219 to $386{ }^{\circ} \mathrm{C}$ at nitrogen atmosphere, in a flow of $100 \mathrm{~mL} \mathrm{~min}{ }^{-1}$. The average activation energy of sewage sludge sample revealed the value of $219 \mathrm{~kJ} \mathrm{~mol}^{-1}$ and that of the mixture $161 \mathrm{~kJ} \mathrm{~mol}^{-1}$, supporting the incorporation of pruning residues in the sewage sludge. During the degradation process, a remarkable increase in activation energy was noticed that ranged from 20 to $70 \%$ conversion in the sewage sludge sample, and regarding the mixture, an almost linear behavior was observed during the decomposition reaction. There was no evidence of kinetic compensation effect in the performed studies. The evaluation of the thermal characteristics, as well as the kinetic study of the degradation of sewage sludge and its mixture with pruning residues, can lead to important insights and contribute to a better use of energy regarding the environmental issues.
\end{abstract}

Electronic supplementary material The online version of this article (doi:10.1007/s10973-017-6374-5) contains supplementary material, which is available to authorized users.

W. C. Nozela

wnozela@yahoo.com.br

1 Department of Analytical Chemistry, Chemistry Institute, São Paulo State University (UNESP), Araraquara, SP, Brazil

2 Department of Chemistry, Institute of Chemistry, UFSCAR, São Carlos, SP, Brazil
Keywords Sanitary waste $\cdot$ Pruning residues - Mixture · Kinetic

\section{Introduction}

The various types of waste generated daily in large centers are solid urban, agricultural, industrial, among others. They are constant objects of studies, as it was discussed a few years ago regarding their proper disposal and/or reuse. In this issue, urban and industrial solid stand out for offering suitable conditions options for generating employment and income [1], as well as being excellent in energy recovering, avoiding environmental impacts due to pollution that they can cause to the environment.

Some solid wastes have been already used widely in power generation, such as agricultural waste, different types of wood and plant waste such as sugarcane [2]. These residues are also commonly called biomass, which can replace fossil fuels in three forms, solid (briquettes, pellets, and char), liquid (ethanol and biodiesel) and gas (production of gas and biogas) [3]. The application of industrial and sanitary wastes as an alternative fuel in power cogeneration has been studied by several authors $[4,5]$.

The process of combining biomass with other wastes aimed at power generation has been studied for a long time as an alternative to prevent that the residues be disposed of in landfills. The combination of biomasses as pine, chestnut and eucalyptus sawdust, pulp waste, coffee husks and grape waste was studied by Gil et al. [6], indicating good results in obtaining energy.

The reactivity of the mixture between the pine sawdust and olive residue, via pyrolysis and combustion, became better due to the higher volatile content present in the olive residue, and this thermal behavior was studied by 
Lajiji et al. [7]. A study on the thermal behavior of residues from sugarcane industry, such as bagasse, filter cake and vinasse, in individual form and combinations of mixtures among themselves using thermogravimetry under the $\mathrm{N}_{2}$, $\mathrm{CO}_{2}, \mathrm{~N}_{2} / \mathrm{O}_{2}$ and $\mathrm{CO}_{2} / \mathrm{O}_{2}$ atmosphere aiming energy reuse was also developed by Silva et al. [8]. They found higher levels of ash in the filter cake and vinasse (47 and 40\%, respectively) compared to bagasse (5\%). The vinasse, in turn, started to decompose at a lower temperature (160 vs. $250{ }^{\circ} \mathrm{C}$ bagasse and filter cake) in atmospheres of synthetic air and $\mathrm{CO}_{2} / \mathrm{O}_{2}$ due to the absence of fibers in their structure. The mass loss events observed in steps at the following temperatures up to 150,310 and $500{ }^{\circ} \mathrm{C}$ are attributed to moisture, decomposition of hemicellulose and cellulose and lignin degradation, respectively. In the $\mathrm{CO}_{2}$ atmosphere, the events occurred at higher temperatures for all samples.

Knowing of the physicochemical and biological characteristics, beyond the origin of different types of waste, guides us as the classification of the same and guides us as to its use. In this sense, the study behavior during the process of degradation, combustion and pyrolysis [9] is necessary for a better reuse. Thermogravimetry (TG) is crucial for providing information in a simple, fast and reliable thermal and kinetic behavior of biomass for the energy recovery and the utilization of sewage sludge, reducing the possible environmental impact.

\section{Objective}

The aim of this study was to determine the activation energy of the sewage sludge and their mixing samples with pruning residue regarding energy reuse using the local linear integral isoconversional method based on interactive theorem for integral average value, analogous to the method of Wanjun-Donghua [10, 11].

\section{Materials and methods}

The samples used in this study were selected from sewage sludge (SS) from the sewage treatment station after thermal drying process at $300{ }^{\circ} \mathrm{C}$, and urban waste prunings (UWP), both from the city of Araraquara/SP. The SS samples were collected at different points of a reservatory at the end of the process, and so, a representative sample of them was obtained after the mixture and dividing into quarters, according to the Techniques Law Brazilian Association (NBR 10007, 2004) [12]. The UWP sample was ground in a knife mill and dried in an oven at $60{ }^{\circ} \mathrm{C}$ for one week. The SS and UWP samples were ground in a cryogenic mill SPEX 6800 to decrease the particle size in accordance with the operation program described in Table 1.

The SS sample was analyzed individually, and a mixture (1:1) of SS and UWP was prepared, resulting in the M sample.

For the kinetic study was used approximately $7 \mathrm{mg}$ of the SS, UWP and M samples, using heating rates of 10.0, 20.0 and $30.0{ }^{\circ} \mathrm{C} \mathrm{min}^{-1}$, $\alpha$-alumina crucible and temperature of $30-700{ }^{\circ} \mathrm{C}$ in a nitrogen atmosphere at a flow rate of $100 \mathrm{~mL} \mathrm{~min}^{-1}$.

The kinetic parameters, activation energy $\left(E_{\mathrm{a}}\right)$ and preexponential factor $(\ln A)$, were obtained through the local linear integral isoconversional method. This method is based on interactive theorem for integral average value, analogous to the method of Wanjun-Donghua, where the kinetics of the reactions of decomposition can be initially described by the differential Eq. (1), given by:

$\frac{\mathrm{d} \alpha}{\mathrm{d} T}=\frac{A}{\beta} \mathrm{e}^{-\frac{\mathrm{R}}{\mathrm{RT}} f(\alpha)}$

Assuming that the parameters $E_{\alpha}, A_{\alpha}$, and the local heating rate $\beta_{\alpha}$ are constants in $[\alpha-\Delta \alpha, \alpha+\Delta \alpha]$, from Eq. (1), we can obtain that:

$\Delta g(\alpha)=\int_{\alpha-\Delta \alpha}^{\alpha+\Delta \alpha} \frac{1}{f(\alpha)} \mathrm{d} \alpha=\frac{A}{\beta} \underset{T \alpha-\Delta \alpha}{\mathrm{T} \alpha+\Delta \alpha} \mathrm{e}^{-\frac{\mathrm{E}}{\mathrm{RT}}} \mathrm{d} T$

where $\Delta g(\alpha)=g(\alpha+\Delta \alpha)-g(\alpha-\Delta \alpha)$ e $g^{\prime}(\alpha)=1 / f(\alpha)$. The function $g$ is known as an integral form of the kinetic model.

By applying the mean value theorem to the integral in Eq. (2),

$\Delta g(\alpha)=\frac{A_{\alpha}}{\beta_{\alpha}}\left(T_{\alpha+\Delta \alpha}-T_{\alpha-\Delta \alpha}\right) \mathrm{e}^{-\frac{\mathrm{E} \alpha}{\mathrm{R} \tau \alpha}}$

For some $\tau_{\alpha}$ in $\left[T_{\alpha-\Delta \alpha}, T_{\alpha+\Delta \alpha}\right]$, rearranging Eq. (3) and applying logarithm lead to

$\ln \left[\frac{\beta_{\alpha}}{\Delta T_{\alpha}(1+\gamma)}\right]=B_{\alpha} \mathrm{e}^{-\frac{\mathrm{E}_{\alpha}}{\mathrm{RT} T_{\alpha}}}$

were $B_{\alpha}=\left[\frac{A_{\alpha}}{\Delta g(\alpha)}\right]$; since $\Delta g(\alpha) g \prime(\alpha)$ and $g \prime(\alpha)=1 / f(\alpha)$ we can obtain that:

$A_{\alpha} \approx \frac{2 \Delta \alpha e^{\mathrm{B}_{\alpha}}}{f(\alpha)}$

Table 1 Operating program used for cryogenic grinding of the samples

\begin{tabular}{ll}
\hline Milling cycles & 2 \\
Pre-freeze & $2.0 \mathrm{~min}$ \\
Milling & $1.0 \mathrm{~min}$ \\
Freezing between cycles & $1.0 \mathrm{~min}$ \\
\hline
\end{tabular}


For a given conversion and a series of $n \geq 3$ nonisothermal experiments carried out at different heating rates $\beta_{\alpha, \mathrm{i}}, i=1,2, \ldots, n$, Eq. (4) can be used to develop a local linear integral isoconversional method.

For the proximate analysis (moisture, organics, fixed carbon and ash contents), approximately $10 \mathrm{mg}$ of the SS, UWP and $M$ samples was used at a heating rate of $50{ }^{\circ} \mathrm{C} \min ^{-1}$ to $110{ }^{\circ} \mathrm{C}$, the $\mathrm{CO}_{2}$ atmosphere at a flow rate of $130 \mathrm{~mL} \mathrm{~min}{ }^{-1}$. It was followed by an isotherm of $15 \mathrm{~min}$ and new heating at $50{ }^{\circ} \mathrm{C} \mathrm{min}^{-1}$ to $600{ }^{\circ} \mathrm{C}$. Then, another 30-min isotherm was applied, and there was an exchange of atmosphere to synthetic air during this isotherm, ending with heating [13].

The equipment used for both analyses, the kinetic study and proximate analysis, was the TG-DTA simultaneously, SDT-2960 from TA Instruments.

The determination of the hight heat value (HHV) of the $\mathrm{SS}$, UWP and M samples was performed in a calorimetric bomb from Parr Instrument Company, Model 1341 Plain Jacket, using approximately $400 \mathrm{mg}$ of each sample mixed with $400 \mathrm{mg}$ of benzoic acid.

\section{Results and discussion}

Figure 1 shows DTG curves for the SS sample in the heating rates $10.0,20.0$ and $30.0{ }^{\circ} \mathrm{C} \mathrm{min}{ }^{-1}$ in a nitrogen atmosphere. The interval of the temperature for the kinetic study of the SS sample was selected between 210 and $390{ }^{\circ} \mathrm{C}$.

Figure 2 presents the DTG curves for sample $\mathrm{M}$ in the heating rates $10.0,20.0$ and $30.0{ }^{\circ} \mathrm{C} \mathrm{min}^{-1}$ in a nitrogen atmosphere. The temperature interval for the kinetic study of the M sample was selected between 240 and $390{ }^{\circ} \mathrm{C}$.

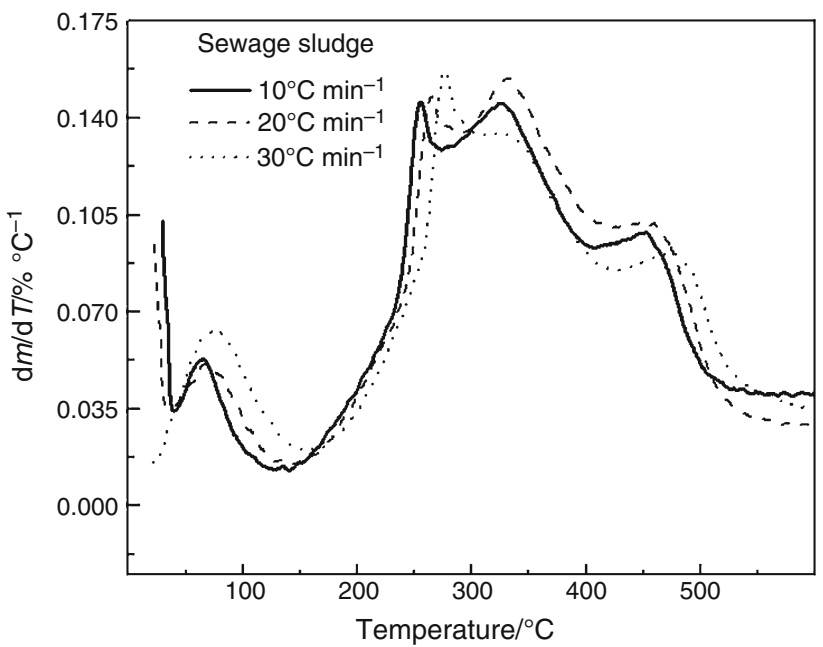

Fig. 1 DTG curves of sample SS in nitrogen atmosphere, heating rates $10.0,20.0$ and $30.0{ }^{\circ} \mathrm{C} \mathrm{min}{ }^{-1}$

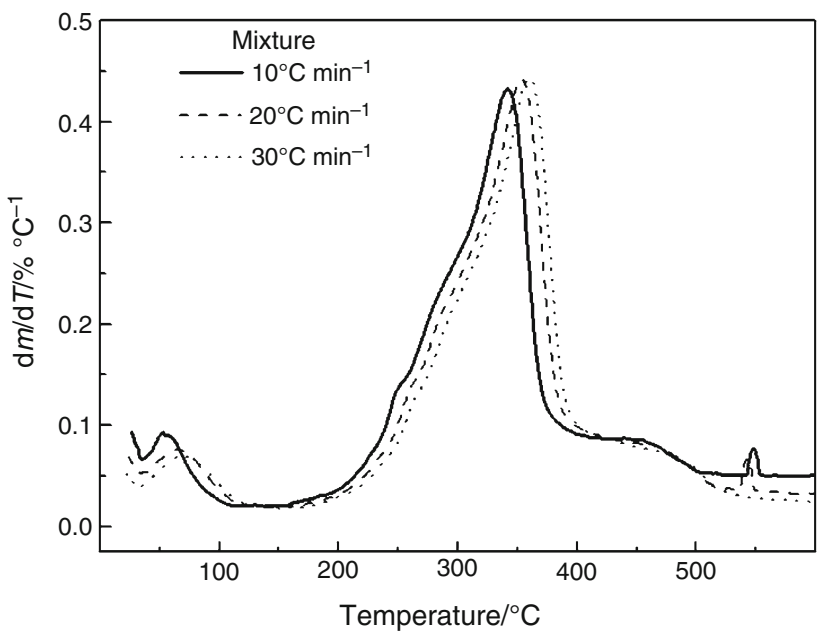

Fig. 2 DTG curves of sample $M$ in nitrogen atmosphere, heating rates $10.0,20.0$ and $30.0{ }^{\circ} \mathrm{C} \mathrm{min}{ }^{-1}$

Figure 3 presents the DTG curves for the UWP sample in the heating rates $10.0,20.0$ and $30.0{ }^{\circ} \mathrm{C} \mathrm{min}{ }^{-1}$ in a nitrogen atmosphere. The temperature interval for the kinetic study of the UWP sample was selected between 250 and $360{ }^{\circ} \mathrm{C}$.

These intervals were correlated with the $(\alpha)$ degree conversion, whose values were comprised between $5 \%$ and $95 \%$ of the reaction occurrence. Then, they were determined for the kinetic parameters $E_{\mathrm{a}}$ and $\ln A$ according to the local linear integral isoconversional method.

The average values referent to the $E_{\mathrm{a}}$ of the SS, UWP and $M$ samples are, respectively, 219, 184 and $161 \mathrm{~kJ} \mathrm{~mol}^{-1}$. The smaller $E_{\mathrm{a}}$ value of $\mathrm{M}$ can be attributed to the presence of pruning residues in the sample, favoring the thermal reactivity, as this material has a high content of volatile organic [14] and that the released heat

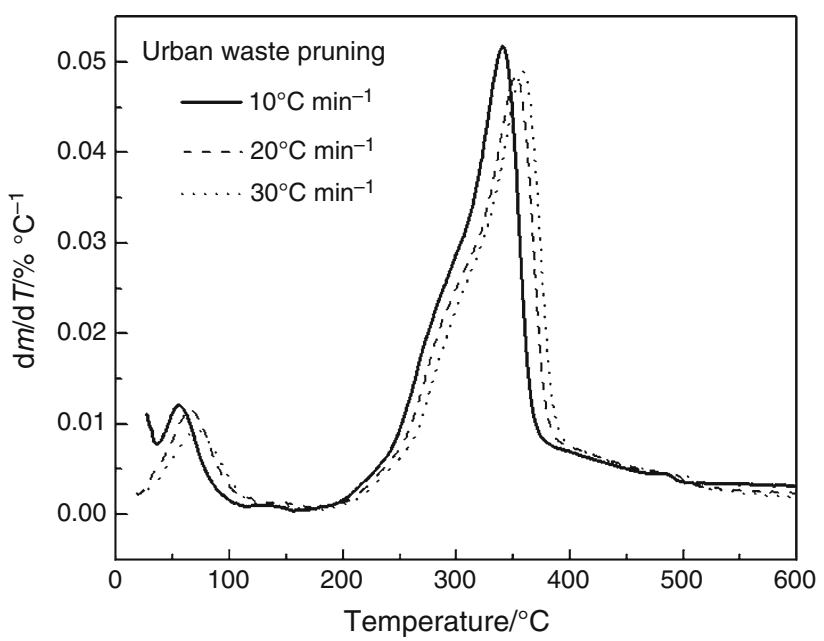

Fig. 3 DTG curves of sample UWP in nitrogen atmosphere, heating rates $10.0,20.0$ and $30.0{ }^{\circ} \mathrm{C} \min ^{-1}$ 
during the reaction contributes for the decreasing of the activation energy.

The obtained variation for the $E_{\mathrm{a}}$ for the SS sample was 138-261 kJ mol${ }^{-1}$, whereas that for the $\mathrm{M}$ sample was $107-175 \mathrm{~kJ} \mathrm{~mol}^{-1}$. A kinetic study in the non-steady state for the calculation of $E_{\mathrm{a}}$ by TG evaluating the thermochemical and thermocatalytic processes of sewage sludge, using the mathematical model "model-free kinetics" applying isoconversional techniques, found the values from 58 to $109 \mathrm{~kJ} \mathrm{~mol}^{-1}$ in the conversion interval of $40-80 \%$ [15]. Values between 30 and $161 \mathrm{~kJ} \mathrm{~mol}^{-1}$ were determined by a conversion interval from 10 to $80 \%$ applying the Kissinger-Akahira-Sunose method [16].

A mixture of $50 \%$ of the mass of sewage sludge and sugar cane bagasse showed the $E_{\mathrm{a}}$ average of $155 \mathrm{~kJ} \mathrm{~mol}^{-1}$. However, only the sludge presented $137 \mathrm{~kJ} \mathrm{~mol}^{-1}$, probably due to the digestion process undergone by this residue during sewage treatment, once that this process is anaerobic [13] and the treatment of sewage sample of this study originates from the aerobic system formed by aeration ponds then settling pond.

Table 2 shows the data for immediate analysis for SS, UWP and M samples. A content of $54.96 \%$ of volatile carbon in $\mathrm{M}$ sample and $40.1 \%$ in the SS sample was determined. The sewage sludge from the city of Lodz in Poland and São Bento do Sul, Santa Catarina/Brazil showed volatile carbon contents slightly higher, $44.6 \%$, [17] and $43.3 \%$ [18]. For similar samplest, it was found to UWP volatile carbon content of 74.9\% [19] and 78.7\% [20] straw of corn, suggesting compatibility between them.

Figure 4 shows the correlation between $E_{\mathrm{a}}$ and degree of conversion for the SS, UWP and M samples. A significant increase in $E_{\mathrm{a}}$ value which is observed from 20 to $70 \%$ degree of conversion, in the SS sample, showing that there is a complexity in the reaction constituents because of the sample type, multiple reactions may occur. The UWP and M sample showed no major changes to $E_{\mathrm{a}}$, remaining constant around 184 and $161 \mathrm{~kJ} \mathrm{~mol}^{-1}$, respectively. This behavior is probably due to the simplest reactions because of the higher amount of volatile material present in the waste pruning, and so there is no evidence of kinetic compensation effect throughout this sample decomposition reaction because for the simple reactions that occurred in the process.

Table 2 Properties of the samples of sewage sludge, urban waste pruning and mixture

\begin{tabular}{lccr}
\hline & SS/\% & UWP/\% & M/\% \\
\hline Moisture & 5.74 & 6.86 & 5.93 \\
Volatile carbon & 40.1 & 67.69 & 54.96 \\
Fixed carbon & 11.01 & 21.55 & 16.75 \\
Ash & 43.15 & 3.90 & 22.36 \\
\hline
\end{tabular}

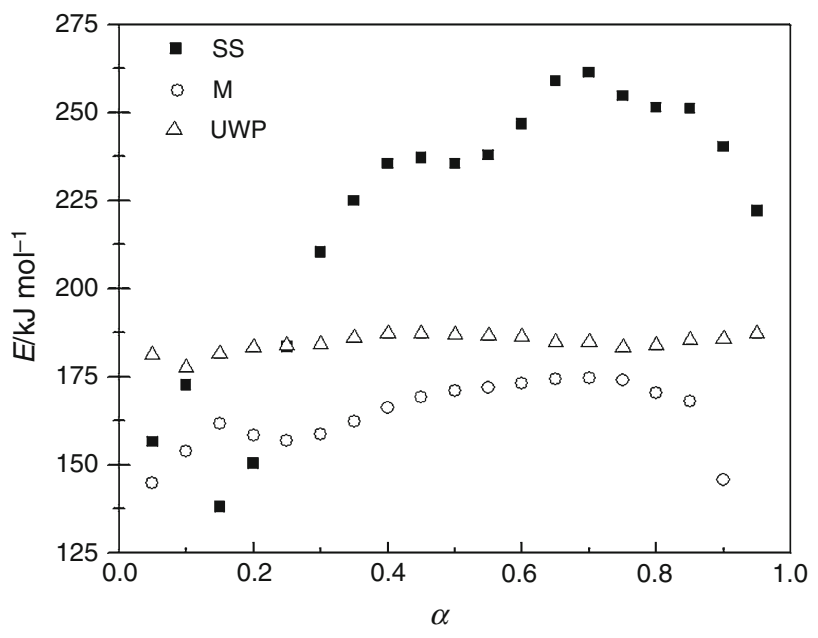

Fig. 4 Relationship between $E_{\mathrm{a}}$ and for the samples SS, M and UWP

Figure 5 shows the correlation between $\ln A$ and $E_{\mathrm{a}}$ for the SS sample. A kinetic compensation effect can be partially evidenced in the interval of $E_{\mathrm{a}}$ between 135 and $237 \mathrm{~kJ} \mathrm{~mol}^{-1}$, equivalent from 20 to $70 \%$ of conversion grade of the SS sample by the linearity between $E_{\mathrm{a}}$ and $\ln A$. Similar behavior with manure samples from landfill in São Carlos/SP-Brazil was also observed by Almeida et al. [21]. In this decomposition, it was observed simple and posterior reactions to this interval, by the complexity of the sample is observed the existence of parallel reactions with different mechanisms [22].

The HHV of the SS, UWP and M samples is shown in Table 3. The high calorific power of the mixture,

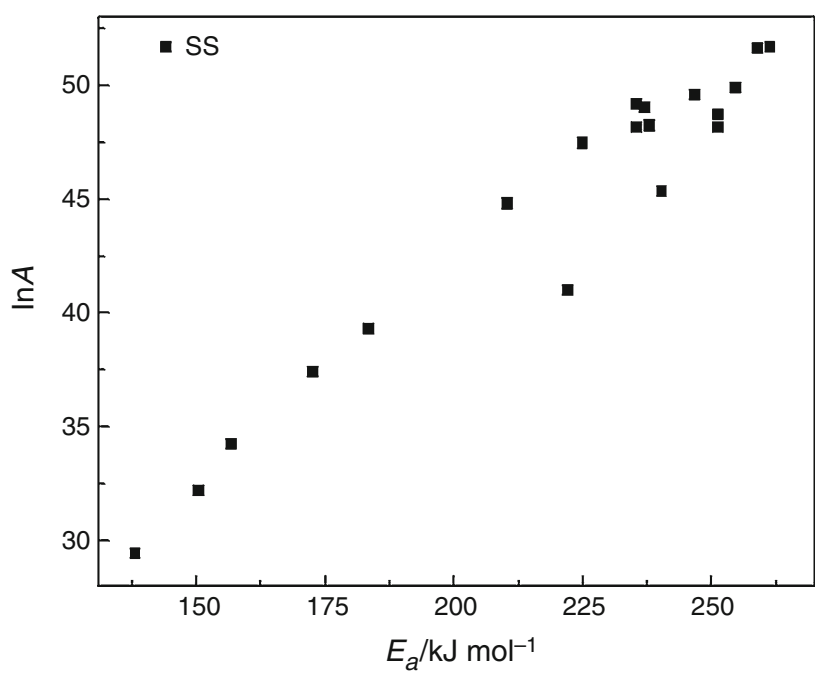

Fig. 5 Relationship between $\ln A$ and $E_{\mathrm{a}}$ for the sample SS

Table 3 HHV determined for samples SS, UWP and M

\begin{tabular}{llll}
\hline & SS & UMP & M \\
\hline $\mathrm{HHV} / \mathrm{kJ} \mathrm{g}^{-1}$ & 15.63 & 13.72 & 20.36 \\
\hline
\end{tabular}


$20.36 \mathrm{~kJ} \mathrm{~g}^{-1}$, in comparison with pure samples, can be explained by the synergism occurred between the SS and UWP samples. It may confirm the data referent to activation energy, the incorporation of pruning waste in sewage sludge favored thermal behavior of the mixture, with a low activation energy and high calorific power, which makes this an interesting mix in the reuse process.

\section{Conclusions}

The kinetic parameters applied from the TG showed that the sludge samples sewage and urban pruning residue have a high activation energy, showing to be more interesting the incorporation of pruning residues for the energetic point of view. The calorific value of this mixture also showed this fact due to the heat released during the decomposition process, showing a synergism between the samples of sewage sludge and urban waste pruning.

The organic carbon contents found in the mixture contributed to confirm the kinetic energy data and calorific power.

The adopted isoconversional method proved to be an effective strategy for providing concrete benefits of sample degradation kinetics and contributed to the implementation of these wastes in the energy recovery, minimizing the environmental impacts of improper disposal of them.

Acknowledgements Authors would like to acknowledge the Department Water and Sewage Autonomous Araraquara and UNESP, Chemistry Institute, Araraquara.

\section{References}

1. Borowski HC, Silveira JL, Ebinuma CD, Ferreira ED. Análise de um modelo de co-geração a partir de resíduos sólidos urbanos. Rev Tec. 2002;23:26-7.

2. Botão SG, Lacava PM. Uso do bagaço de cana-de-açúcar para cogeração de energia elétrica no Estado de São Paulo e a comercialização do excedente da energia gerada. Rev Biosci. 2003;9:17-37.

3. Kol MP, Hoi WK. Sustainable biomass production for energy in Malaysia. Biomass Bioenergy. 2003;25:517-29.

4. De Sena RF. Avaliação da biomassa obtida pela otimização da flotação de efluentes da industria de carnes para geração de energia. 2005. 94 f. Dissertação de Mestrado. Universidade federal de Santa Catarina. Florianópolis. 2005.
5. Sanger M, Werther J, Ogada $J$. $\mathrm{NO}_{\mathrm{x}}$ and $\mathrm{N}_{2} \mathrm{O}$ emission characteristics from fluidized bed combustion of semi-dried municipal sewage sludge. Fuel. 2001;80:167-77.

6. Gil MV, Oulego P, Casal MD, Pevida C, Pis JJ, Rubiera F. Mechanical durability and combustion characteristics of pellets from biomass blends. Bioresour Technol. 2010;101:8859-67.

7. Lajiji M, Limousy L, Jeguirim M. Physico-chemical properties and thermal degradation characteristics of agropellets from olive mill by-products/sawdust blends. Fuel Process Technol. 2014;1126:215-21.

8. Silva DR, Crespi MS, Crnkovic PCGM, Ribeiro CA. Pyrolysis, combustion and oxy-combustion studies of sugarcane industry wastes and its blends. J Therm Anal Calorim. 2015;121:309-18.

9. Zheng G, Kozinski JA. Thermal events occurring during the combustion of biomass residue. Fuel. 2000;79:181-92.

10. Wanjun T, Donghua C. An integral method to determine variation in activation energy with the extent of conversion. Thermochim Acta. 2005;433(1-2):72-6.

11. Torquato LDM, Braz CEM, Ribeiro CA, Capela JMV, Crespi MS. Kinetic study of the co-firing of bagasse-sludge blends. J Therm Anal Calorim. 2015;121:499-507.

12. Associação Brasileira de Normas Técnicas. NBR 10.007amostragem de resíduos sólidos. Rio de Janeiro. 2004.

13. Torquato LDM, Crnkovic PM, Crespi MS, Ribeiro CA. New approach for proximate analysis by thermogravimetry using $\mathrm{CO}_{2}$ atmosphere. J Therm Anal Calorim. 2017;128:1-14.

14. Chiang KY, Chien KL, Lu CH. Characterization and comparison of biomass produced from various sources: suggestions for selection of pretreatment technologies in biomass-to-energy. Appl Energy. 2012;100:164-71.

15. Pedroza MM. Bio-óleo e biogás da degradação termoquímica de lodo de esgoto doméstico em cilindro rotativo. 236f. Tese doutorado em engenharia química. Universidade Federal do Rio Grande do Norte, Natal. 2011.

16. Magdziarz A, Wilk M. Thermal characteristics of the combustion process of biomass and sewage sludge. $\mathrm{J}$ Therm Anal Calorim. 2013;114:519-29.

17. Nowicki L, Antecka A, Bedyk T, Stolarek P, Ledakowicz S. The Kinetics of gasification of char derived from sewage sludge. J Therm Anal Calorim. 2011;104:693-700.

18. Borges F, Sellin N, Medeiros SHW. Caracterização e avaliação de lodos de efluentes sanitário e industrial como biomassa na geração de energia. Ciência e Engenharia. 2008;17:27-32.

19. Kumar A, Wang L, Dzenis YA, Jones DD, Hanna MA. Thermogravimetric characterization of corn stover as gasification and pyrolysis feedstock. Biomass Bioenergy. 2008;32:460-7.

20. Demirbas A. Calculation of higher heating values of biomass fuels. Fuel. 1997;76:431-4.

21. Almeida S, Lima EM, Crespi MS, Ribeiro CA, Schalch V. Kinetic studies of urban solid residues and leachate from sanitary landfill. J Therm Anal Calorim. 2009;97:529-33.

22. Vyazovkin S, Burnham AK, Criado JM, Peres-Maqueda LA, Popescu C, Sbirrazzuoli N. ICTAC Kinetics Committee recommendations for performing kinetic computations on thermal analysis data. Thermochim Acta. 2011;520:1-19. 